\title{
Refusing Without "No": The Way Lecturers Indicate Disagreement of Asian Efl Learners In Speaking Class
}

\author{
Niyan Wahyu Novalina ${ }^{1, a^{*}}$, Slamet Setiawan ${ }^{1, b}$, Ali Mustofa ${ }^{1, c}$ \\ 1 Language and Literature Education Study Program, Postgraduate Program, State University of Surabaya, Surabaya, 60213, Indonesia \\ a niyan.17070835048@mhs.unesa.ac.id; b Slamet.Setiawan@unesa.ac.id; c Ali.Mustofa08007@gmail.com \\ *Corresponding Author \\ Whatsapp number: [085732700069]
}

How to Cite : Novalina, N., W., Setiawan, S., Mustofa, A. (2019). Refusing Without "No": The Way Lecturers Indicate Disagreement of Asian Efl Learners In Speaking Class. International Journal for Educational and Vocational Studies, 1 (7), 728-732

\section{ARTICLE HISTORY}

Received: 13 August 2019

Revised: 23 September 2019

Accepted: 20 October 2019

\section{KEYWORDS}

Way Lecturers Indicate;

Disagreement of Asian EFL;

Asian EFL Learners;

Speaking Class;

\begin{abstract}
Refusal is a part of face threatening act which belong to one of politeness. Refusal is being phenomenon in language education especially in classroom. Learners often refuse lecturers' instruction when they teach in the class. One of refusal strategies is disagreement which is a part of traditional politeness theories. In language teaching, not only learners but also lecturers also often disagree with the learners and the disagreement is also necessary for the learners. In this study, lecturers used linguistic markers to express disagreement in mitigating the face threatening. In Asian context, there were vary disagreements which were expressed by Asians. In this study, head movement and hand gesture is analyzed as disagreement of linguistic markers to stress the utterances in implicit meaning. They might become the way of disagreement communication for lecturers who taught language education in EFL context. This study observed lecturers' disagreements in Asian language classroom context with heterogeneous learners (Indonesian, Malaysian, and Thai EFL learners). The result of this study is lecturers disagree for dispreferred options in certain aspect and the silence was minimized to avoid negative gesture or head movement. The way of lecturer in disagreement influenced by western culture when respond the learners' refusal act.
\end{abstract}

This is an open access article under the CC-BY-SA license.

\section{INTRODUCTION}

Human as public-spirited individual need other people to help them living because people is a part of social community so they need one another to fulfill their needs. As a part of community, people are needed to communicate and interact with other people. When people communicate with other people, sometime, they have certain hidden meaning and motive. Based on Yule, (1996), the study of meaning in interaction covers theories that relate to the meaning behind words in linguistic field is pragmatics. It means every language has its own role to express what language they speak to in different hearer. Every people also has own system to express politeness in different culture and different ways of speech acts. According to Searle, (1976) defines speech acts as the basic units of linguistic communication that take part as the media which contains acts including refusal.

Refusal is a part of speech act which need to be tackled cautiously. Refusal is a face threatening act and it is important that refusal strategies be used to soften to save the hearer's face. Refusal refers to a disapproval of the idea of hearers and the threat to hearer' face (Bebee et al., 1990 as cited Septiany, 2013). Refusal is used by people to express a rejection and disagreement of certain case. Refusal is also used for negotiation which has a function to keep other people face. In diverse community such as Southern Asia where English is as foreign language and Asian need to be aware of different refusal strategies politely. Furthermore, Asian learners of English as foreign language need to be acquainted with the best refusal strategies which they may need to use in different situations. In the same line, lecturers also need to have an awareness of the refusal strategies which are adopted among learners in order to know the meaning of refusal strategies used by them.

This study investigates refusal without saying no among Asian EFL learners who lecturers indicate their disagreement in speaking class. Their refusal determines the way of Asian EFL learners negotiate or disagree about certain case in speaking class based on their own culture. In particular, the result of the study can be used to know and understand about the way of Asian EFL learners in 
refusing non-verbally in speaking class. Also, the results are used as the reference to investigate the refusal strategies phenomena in other parts in Asia.

This paper is organized into six sections. The first section is introduction which is followed by a brief theoretical framework presentation in section two. The third section discusses the method of the study. The way of south Asian EFL learners refuse non-verbally is addressed in section four and some evidence of using refusal for showing politeness in south Asian context is in section five before summary.

\section{METHODS}

The study was conducted from November 2018 to March 2019. This study was conducted in two different universities of international class. The learners were each eighteen learners. In this part also explained about the specific usage of politeness strategies in refusal and disagreement. Refusal definition is also being a part of this literature. Some previous studies are also included and will be followed by what researcher found in the literature about the fact that might influence refusal strategies.

\subsection{Politeness and Disagreement}

Brown and Levinson (1987), politeness is self-image or face of each person. Face means how interlocutor behave to others for keeping the face of other. There are positive and negative face which exist on politeness. Positive politeness is the way of keeping positive face of hearers and has a close relation with the speaker. In other side, negative politeness is described as the free action or direct statement which never care of the hearers' face. In the same line, Disagreement is one of parts in politeness and refusal strategies which is described as, "the expression of a view that differs from that expressed by another speaker" (Sifianou, 2012: 1), disagreement can be as positive image or negative image and has a potential to create conflict which need more pay attention to the interlocutors. The interlocutor's positive face is threatened when their actions/ideas are questioned (Brown and Levinson, 1987).

Disagreement is one of politeness traditional theories in impolite act to keep interlocutors' face by using its strategies. An additional strategy, bald on record, does not mitigate the disagreement but is linked to efficient communication, such as using imperatives (Brown and Levinson,1987: 95). In everyday communication, especially disagreement, the speakers also use silence as the disagreement marker.

\subsection{Refusals}

Different researchers have provided different definitions for refusal acts. For example, Felix-Brasdefer, (2008) states that refusals are "complex speech acts that require not only long sequences of negotiation and cooperative achievements, but also face saving maneuvers to accommodate to noncompliant nature of the act" (p. 196).
Moreover, refusals are viewed as face threatening acts that need to be mitigated in order not to negatively affect the addressee. For instance, Mashiri, (2002) explains that the act of refusal "occurs when a speaker directly or indirectly says "no" to a request, invitation, offer, or suggestion" (p121). Furthermore, Hei, (2009) believes that saying "no" to others includes the risk of offending them and threatening their face. Therefore, "some speakers may be indirect so as to mitigate the face threatening acts whilst also preserving the face of the hearer" Hei,(2009). Therefore, the importance of refusals as speech acts stems from the fact that they are face-threatening acts that might offend others if not accompanied by certain strategies that might help to soften such an act. Moreover, nonverbal strategies are commonly used when it comes to refusal strategies.

\subsection{Gestures}

Refusal can be expressed by the speakers in non-verbal action which is included on disagreement. Kakava's describe non-verbal refusal is "an oppositional stance (verbal or non-verbal) to an antecedent verbal (or non-verbal) action". By using non-verbal become a little attention this far because silence is meaningless for certain person. Furthermore, gesture is an alternative to use in expressing disagreement. The disagreement can be expressed by hand gesture and possibly also in the head movement (McNeill, 2016). Moreover, politeness focus on gesture only few studies, even though it is known as linguistic politeness gestures (Kita, 2009). Gesture movements can be described as sign language which is followed by mime and emblems. In the same line, hand gesture is resembling the content of speech that is ironic which is recognized to implicit meaning in the speakers in the same reaction of utterances. The gesture and utterance are both important for understanding communication interaction (Ozyürek, 2014).

\subsubsection{Pragmatic gestures and head movement}

Pragmatic gestures are used in communicative act or in management of communication act. Ladewig (2013) define new meaning about "recurrent gestures" is one of pragmatic gestures which have been conventionalized the meaning in deriving from particular culture and express a meaning making. Head signs or movements are crucial part in communicative act such as disagreement and refusal in head movement (Harrison, 2013; Kendon, 2002), even though, head movement belong to semantic, discourse and interactive function. Head movement often convey as positive and negative attitude of the speakers (Kobayashi et al., 2017). Moreover, when the speakers use nods to mitigate the disagreement or shake to indicate bald on record disagreement. In most western country, the head shake is interpreted "no", it means the speakers disagree about something but sometimes head shake interpreted as "very" or a lot" (McClave, 2000) and one of country in Europe, head shake, sometime, indicate agreement in particular case (Calbris, 2011), although the consensus is 
that the majority of head shakes are likely to accompany a negative utterance, often with a negating gesture (Harrison, 2013; Kendon, 2002).

\subsection{Data Analysis}

This study used qualitative and quantitative methods. This objective of study was identifying how lecturers disagree with their EFL learners in Asian context of speaking class. This study analyzed non-verbal disagreement and linguistic markers and it focused on hand gesture and head movement in silence which was as negative disagreement. Then, the hypothesis was lecturers use disagreement toward linguistic markers which use gesture in conventional way. The data collection used video recorded from 6 lecturers in the same disciplines as speaking lecturers in Islamic university. The analysis data was quantitative framework which is followed by (Brown and Levinson, 1987) and (Rees- Miller, 2000). It is used to get rich data in linguistic markers which was used in the types of disagreement in non-verbal context. For describing other element in communicative interaction of disagreement used qualitative. It could be a form of head gesture, and other disagreement of implicit meaning.

\section{RESULTS AND DISCUSSION}

\subsection{Disagreement of Using Linguistic Markers}

In eight hours, six teachers were recording in two meetings. One disagreement act was found in one of the sessions. In 40 cases of disagreement which was observed with 110 linguistic markers. It was included laughs and silences. This data was analyzed in quantitative but it was also important that disagreement acts were identified in whole session by using observation. For instance, Brown and Levinson (1987) had classified repetition as agreement could be a part of positive politeness to show solidarity. There were 110 linguistic markers that specifically identified. The linguistic markers were found about 110 which included in this observation. Table.1 was the types of linguistic markers as interpreting linguistic information.

Table 1. Disagreement of using linguistic markers.

\begin{tabular}{cccc}
\hline Type of disagreement & Total & $\begin{array}{c}\text { linguistic and } \\
\text { non-linguistic marker }\end{array}$ & No. \\
\hline Bald-on record & & But & 8 \\
\hline $\begin{array}{c}\text { Mitigated } \\
\text { disagreement }\end{array}$ & (positive & No/not/not really & 15 \\
\hline & politeness) & Other statements & 5 \\
\hline & & Positive comments & 17 \\
\hline & & Repetition & 17 \\
\hline & & Well & 13 \\
\hline & & Ehm/eh & 9 \\
\hline & & Jokes & 3 \\
\hline & (off-record) & Inclusion & 8 \\
\hline & & Rhetoric & 1 \\
\hline & (negative & Smiles/laughs & 3 \\
\hline & & Silence & 2 \\
\hline
\end{tabular}

\begin{tabular}{|c|c|c|c|}
\hline & & Avoiding I and you & 2 \\
\hline & & Sorry & 1 \\
\hline & 14 & Maybe/ possibly & 1 \\
\hline & & $\begin{array}{l}\text { I don't know/l don't think } \\
\text { so }\end{array}$ & 7 \\
\hline \multirow[t]{4}{*}{ Aggravated } & & Personal opinion & 0 \\
\hline & 3 & Intensifiers & 0 \\
\hline & & Judgemental & 2 \\
\hline & 110 & & \\
\hline
\end{tabular}

Adapted from Brown and Levinson, 1987: 102e227 and Rees-Miller, 2000: 1095

From the table.1, 110 personal linguistic markers in disagreement is $20 \%$ which is classified as bald-on record or unmitigated disagreement. The statement of but belong to contrary disagreement which explained the reason of the content. Other disagreement markers in mitigating disagreement act got high achievement in this case. The amount of this case is $92 \%$ which is considered as mitigation of lecturers' disagreement by using linguistic markers. The hand movements and gestures of lecturers in this study followed by British approach in disagreement which propose by Netz and Lefstein (2016).

\subsection{Gestures}

Gesture percentages of this study which was found is about $34 \%$ of disagreement linguistic markers that mentioned in table.1. The only strokes gestures were recorded and were taken into account as the information of the gestures (Kendon, 2004). See Fig. 1.

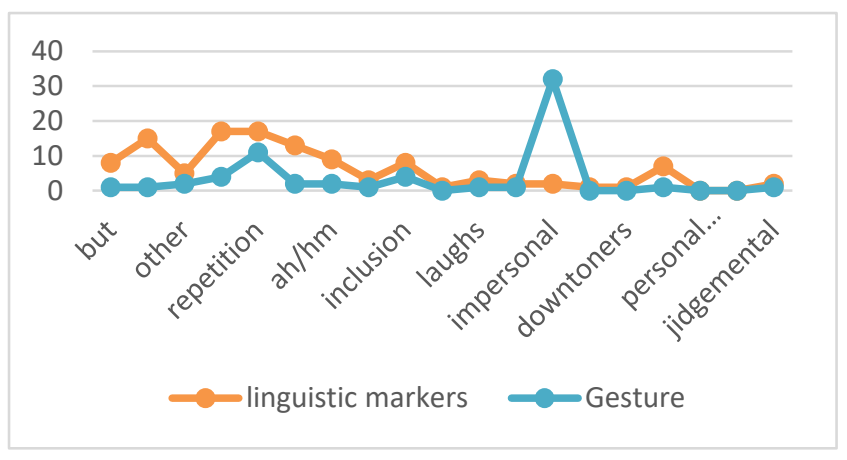

Figure 1: Gestures with disagreement markers

The interesting note in the result is bald-on record which is few gestures than others. The pragmatics gesture also analyzed in the utterances mark or stress. Whereas, in daily conversation this linguistic negation was avoided, such as in daily communication. The characteristic of Asian language education context, the negative assessments and negative statements are dispreferred. Learners have been told to listen an audio about public places and identify them. The learners presented about the places and the lecturers confused by the statement and the lecturers started to repeat the statement and instructions. The lecturer realized that the learners was interrupting and talking much at that time and the lecturers used gestures to express those actions. Gesture 1 of first lecturer is palm open, left hand up, finger pointing and facing students. 
Gesture 2 of second lecturers is head shake, hand up, and palm facing down. Gesture 3 of third lecturer is rotated her body toward the board, lifts both arms toward the board and continue likes gesture 1 . Gesture 4 of fourth lecturer is the right hand from a first toward the leaners. Gesture 5 of fifth lecturers is finger pointing and palm facing down. Then, gesture 6 of sixth lecturer is the right hand up above the head.

As the gestures above, the disagreement with gestures are various and they have varied function. Several of them are deictic that is pointing the student, iconic is describing to the content and others use pragmatics meaning making. They expressed repeated disagreement. From that case, lecturers are very crucial to express disagreement when they disagree with the learners, they accepted correct answers partly then explain the learners in the classroom as their working. The significance gesture could be related to lecturers' efforts to conclude the learners in discussion and other strategies to create effect of.

\subsection{Disagreement on Head movements}

The success of communication also be a part of head movements, but the process of hand movements is not similar with implying speech as hand gestures (Meister et al., 2003). People are likely use head movement than gesture for showing disagreement markers of personal disagreement Woolf et al., (2009), see Fig. 2. This case is only repetition which observe in high number of both head.

Although the lecturer disagrees with the students, they nod, may be to mitigate disagreement stress in linguistic markers in bald-on record such as but. It has the different statements which mitigate the downtowners which is expressed like I would talk about, this case built negative face and in other side, it was soften with not. The lecturers keeping their identity as knowledge holder but mitigating is disagreement threat which might pose. The lecturer gestures seem to be deictic one and it is not negating. Mitigate strategy of disagreement indicate lecturers are very aware of learners' identities and need to maintain a positive environment (Lopez- Ozieblo, 2015).

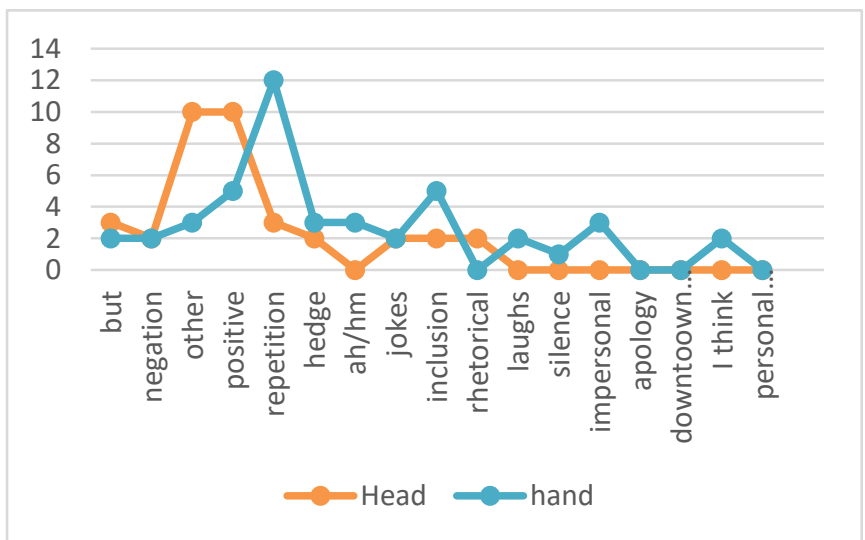

Figure 2. Types of head movements and hand gestures

Even though less than fifth head movements, 15\% was head movement which show negative meaning of English as foreign language use and they were limited in using negation markers. Other case of head shake includes head gesture and the body also moved with the head gesture. Head movements do not follow by direct apologize, down toners, and other negative face (see Fig. 3). The lecturers used positives politeness and they used negative disagreement. It means the lecturers are more efficient in supporting learners with nods. When learners' answer is incorrect and the lecturers still provide positive encouragement.

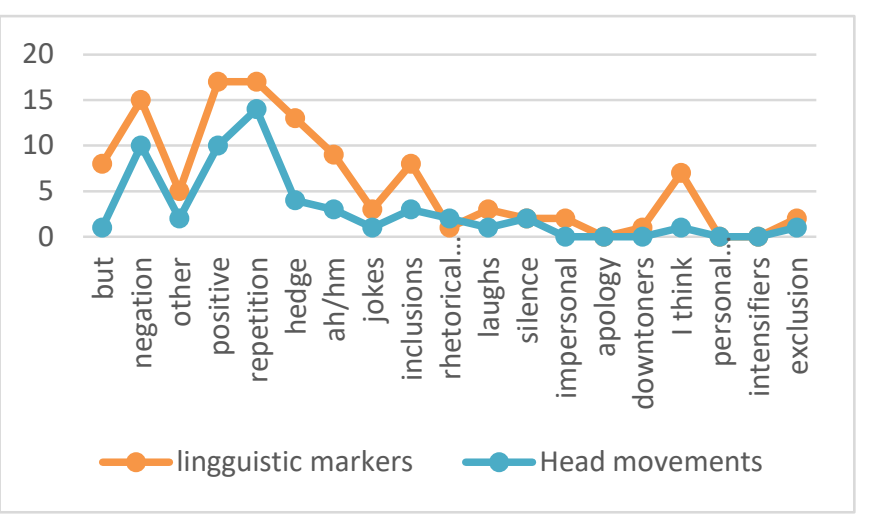

Figure 3. Head movements.

Based on figure.3 above, positive politeness and repetition are higher than others. It means the lecturers use head movement as linguistic marker to keep negative face of hearers when respond the learners in language education class. Even though the cases of learners' refusal are not correct but the lecturers still use positive and repetition to show their disagreement as their respond to the learners.

\section{CONCLUSION}

The result of this study is contrary to the hypothesis. The hypothesis is answered that in Asian EFL learners' language education context, the lecturers who disagree with the learners are influenced by British or western culture. Then, the lecturers are highly mitigated. In pedagogical context, it is expected that silence and negative hand gesture or shake of head is implemented in the classroom. In this study, the lecturers mitigated disagreement by using linguistic markers and also nods to support learners to success in communication and interaction among them. Moreover, negative disagreement has a function to minimize avoiding negating gesture. The mitigates disagreement is dispreferred action which lecturers tried to pose the learners in correct expectation answer. The mitigate disagreement should be interpreted as cultural context. That is why the lecturer should be more willing when they disagree with the learners' refusal.

It is far from the perfect in understanding disagreement with linguistic markers which include hand movements and gestures. In the same line, the suggestion for the further researchers use disagreement in the classroom by using verbal disagreement. In Asian EFL language context, lecturers mitigate disagreements for minimizing any 
potential threat to the learners' face and keeping learners' motivation. Therefore, these result are very important for lecturer to mitigate any damage of lecturers' negative face and for the learners, this is very beneficial for keeping positive face and both of them could reinforce their knowledge-based roles.

\section{REFERENCES}

Angouri, Jo, Locher, Miriam A., (2012). Theorising disagreement. J. Pragmat. 44 (12), 1549e1553.

Blum-Kulka, Shoshana, Blondheim, Menahem, Hacohen, Gonen, (2002). Traditions of dispute: from negotiations of talmudic texts to the arena of political discourse in the media. J. Pragmat. 34 (10), $1569 \mathrm{e} 1594$.

Bressem, Jana, Müller, Cornelia, (2013). The family of away gestures: negation, refusal, and negative assessment. In: Müller, C., Cienki, A., Fricke, E., Ladewig, S.

H., McNiell, D., Tebendorf, S. (Eds.), Body - Language Communication. Walter de Gruyter, Berlin, pp. $1098 \mathrm{e} 1124$.

Brown, Penelope, Levinson, Stephen C., (1987). Politeness: Some Universals in Language Usage. Cambridge University Press, Cambridge.

Calbris, Genevi_eve, (2011). Elements of Meaning in Gesture. John Benjamins Publishing, Amsterdam.

Cassell, Justine, McNeill, David, McCullough, Karl-Erik, 1999. Speech-gesture mismatches: evidence for one underlying representation of linguistic and nonlinguistic information. Pragmat. Cognit. 7 (1), $1 \mathrm{e} 34$.

Cazden, Courtney, (1986). Classroom discourse. In: Wittrock, Merlin C. (Ed.), Handbook of Research on Teaching. MacMillan Publishing Company, New York, pp. $432 \mathrm{e} 463$.

Church, R. Breckinridge, Goldin-Meadow, Susan, (1986). The mismatch between gesture and speech as an index of transitional knowledge. Cognition 23 (1), $43 \mathrm{e} 71$.

Goldin-Meadow, Susan, (1997). When gestures and words speak differently. Curr. Dir. Psychol. Sci. 6 (5), $138 \mathrm{e} 143$.

$\mathrm{Gu}$, Yueguo, (1990). Politeness phenomena in modern Chinese. J. Pragmat. 14 (2), $237 \mathrm{e} 257$.

Haugh, Michael, (2007). The Discursive Challenge to Politeness Research: an Interactional Alternative. Walter de Gruyter, Berlin, pp. 295e317.

K_ad_ar, D_aniel Z., (2017). Politeness, Impoliteness and Ritual. Cambridge University Press, Cambridge.

Kakava, Christina, (1993). Negotiation of Disagreement by Greeks in Conversations and Classroom Discourse (Unpublished doctoral dissertation). Georgetown University, Georgetown, The United States of
America.

Kendon, Adam, (2002). Some uses of the head shake. Gesture 2 (2), 147e182.

Kerssen-Griep, Jeff, (2001). Teacher communication activities relevant to student motivation: classroom facework and instructional communication competence. Commun. Educ. 50 (3), 256e273.

Kita, Sotaro, (2009). Cross-cultural variation of speech-accompanying gesture: a review. Lang. Cognit. Process. 24 (2), $145 \mathrm{e} 167$.

Kotthoff, Helga, (1993). Disagreement and concession in disputes: on the context sensitivity of preference structures. Lang. Soc. 22 (2), $193 \mathrm{e} 216$.

Ladewig, Silva, (2013). Recurrent gestures. In: Müller, C., Cienki, A., Fricke, E., Ladewig, S.H., McNeill, D., Tebendorf, S. (Eds.), Body - Language Communication. Walter de Gruyter, Berlin, pp. $1558 \mathrm{e} 1574$.

Locher, Miriam A., (2004). Power and Politeness in Action: Disagreements in Oral Communication. Walter de Gruyter, Berlin.

McClave, Evelyn Z., (2000). Linguistic functions of head movements in the context of speech. J. Pragmat. 32 (7), $855 \mathrm{e} 878$.

McKinnon, Sean, Prieto, Pilar, (2014). The role of prosody and gesture in the perception of mock impoliteness. J. Politeness Res. 10 (2), 185e219.

McNeill, David, (2005). Gesture and Thought. University of Chicago Press, Chicago.

McNeill, David, (1992). Hand and Mind: what Gestures Reveal about Thought. University of Chicago Press, Chicago.

Netz, Hadar, (2014). Disagreement patterns in gifted classes. J. Pragmat. 61, $142 \mathrm{e} 160$.

Watts, Richard J., (2003). Politeness. Cambridge University Press, Cambridge.

Witt, Paul L., Kerssen-Griep, Jeff, (2011). Instructional feedback I: the interaction of facework and immediacy on students' perceptions of instructor credibility. Commun. Educ. 60 (1), 75e94.

Wong, Ruth M.H., (2011). Developing teacher awareness of language use and language knowledge in English classrooms: four longitudinal cases. Electron. J. Foreign Lang. Teach. 8 (1), $19 \mathrm{e} 38$. 